\title{
Interactions of TLR4 and PPARY, Dependent on AMPK Signalling Pathway Contribute to Anti-Inflammatory Effects of Vaccariae Hypaphorine in Endothelial Cells
}

\author{
Haijian Sun Xuexue Zhu Wei Lin Yuetao Zhou Weiwei Cai Liying Qiu \\ Department of Basic Medicine, Wuxi School of Medicine, Jiangnan University, Wuxi, China
}

\section{Key Words}

Endothelial inflammation • LPS • PPARY • TLR4 • AMPK

\begin{abstract}
Background /Aims: Accumulating evidence indicates that endothelial inflammation is one of the critical determinants in pathogenesis of atherosclerotic cardiovascular disease. Our previous studies had demonstrated that Vaccariae prevented high glucose or oxidative stresstriggered endothelial dysfunction in vitro. Very little is known about the potential effects of hypaphorine from Vaccariae seed on inflammatory response in endothelial cells. Methods: In the present study, we evaluated the anti-inflammatory effects of Vaccariae hypaphorine (VH) on lipopolysaccharide (LPS)-challenged endothelial EA.hy926 cells. The inflammatory cytokines including tumor necrosis factor- $\alpha$ (TNF- $\alpha$ ), interleukin-1 $\beta$ (IL-1 $\beta$ ), monocyte chemoattractant protein 1 (MCP-1) and vascular cellular adhesion molecule-1 (VCAM-1) were measured by real-time PCR (RT-PCR). The expressions of adenosine monophosphateactivated protein kinase (AMPK), acetyl-CoA carboxylase (ACC), toll-like receptor 4 (TLR4), peroxisome proliferator-activated receptor $\gamma$ (PPAR $\gamma$ ) were detected by Western blotting or immunofluorescence. Results: We showed that LPS stimulated the expressions of TNF- $\alpha$, IL$1 \beta$, MCP-1, VCAM-1 and TLR4, but attenuated the phosphorylation of AMPK and ACC as well as PPARY protein levels, which were reversed by VH pretreatment. Moreover, we observed that LPS-upregulated TLR4 protein expressions were inhibited by PPARY agonist pioglitazone, and the downregulated PPARY expressions in response to LPS were partially restored by knockdown of TLR4. The negative regulation loop between TLR4 and PPAR $\gamma$ response to LPS was modulated by AMPK agonist AICAR (5-Aminoimidazole-4-carboxamide riboside or acadesine) or A769662. Conclusions: Taken together, our results suggested that $\mathrm{VH}$ ameliorated LPS-induced inflammatory cytokines production in endothelial cells via inhibition of TLR4 and activation of PPAR $\gamma$, dependent on AMPK signalling pathway.

H. Sun, X. Zhu and W. Lin contributed equally to this work.

Liying Qiu, M.D., Ph.D., Professor, Associate Dean
Department of Basic Medicine, Wuxi Medical School, Jiangnan University, Wuxi, Jiangsu 214122 (China)

Tel. +86-510-85328605, Fax +86-510-85328605, E-Mail qiulydoc@163.com 


\section{Introduction}

Endothelial cells are critical components of blood vessel that play vital roles in the regulation of vascular homeostasis [1, 2]. The functional destruction in endothelial cells contributes to the development and progression of vascular disease [3]. The endothelial dysfunction has been identified to be a high risk factor for cardiovascular diseases [4]. The inflammatory response produces numerous inflammatory mediators to accelerate the apoptosis of endothelial cells, and vascular permeability [5]. The endothelial cell activation in response to inflammatory stimuli is an initial event in diabetic retinopathy [6] and atherosclerosis [7].

Endothelial dysfunction can be modulated by various stress signals in which inflammation plays an essential role [8]. On the other hand, endothelial dysfunction is fundamentally responsible for prothrombotic and proinflammatory state of the vasculature $[9,10]$. Inflammation disrupts normal functionality of the endothelial cells, contributing to the development and progression of cardiometabolic diseases [11]. Prevention of excessive endothelial inflammation may provide promising approaches for treatment of inflammationrelated cardiovascular diseases [12].

Complementary and alternative medicine has attracted tremendous attention due to their anti-inflammatory and antioxidative properties $[13,14]$. Various herbs are currently employed to treat inflammatory disorders [15]. The increasing documents have suggested that complementary and alternative therapeutic strategies are widely used to ameliorate inflammatory state in cardiovascular disorders including atherosclerosis $[13,16]$. Vaccarin is one of the major flavonoid glycoside in Vaccariae seed, which is believed to treat vascular diseases. Our previous studies have revealed that hydrogen peroxide-induced decrease in endothelial cell viability was selectively restored by vaccarin treatment [17]. Vaccarin is able to protect the vascular endothelial cells from injury triggered by high glucose [18]. Reconstruction of bacterial cellulose-vaccarin promotes wound healing in mice [19]. Hypaphorine from different marine sources is shown to possess anti-inflammatory properties [20]. Hypaphorine was a key monomer of Vaccaria segetalis. However, whether and how vaccariae hypaphorine $(\mathrm{VH})$ is involved in endothelial inflammation, remains largely unknown. In this study, we demonstrated for the first time that VH attenuated LPS-mediated endothelial inflammation via regulation of toll-like receptor 4 (TLR4) and peroxisome proliferator-activated receptor $\gamma(\operatorname{PPAR} \gamma)$, dependent on adenosine monophosphateactivated protein kinase (AMPK) activation.

\section{Materials and Methods}

\section{Reagents and chemicals}

Vaccaria hypaphorine (VH, Fig. 1) was purchased from Shanghai Shifeng technology Co., Ltd., China. Human endothelial EA.hy926 cells were obtained from American Type Culture Collection (Rockville, MD, USA). RNAiso Plus reagent was purchased from Takara Co. (Takara, Otsu, Shiga, Japan). Lipopolysaccharide (LPS), pioglitazone, 5-Aminoimidazole-4-carboxamide riboside or acadesine (AICAR) were purchased from Sigma Chemical Co. (St Louis, MO, USA). AMPK inhibitor compound C was obtained from Selleckchem Chemicals (Houston, TX, USA). AMPK activator A769662 was purchased from Tocris Biosciences (Ellisville, MO, USA). Antibodies against GAPDH and goat anti-rabbit IgG H\&L (Alexa Fluor ${ }^{\circledR} 488$ ) were purchased from Abcam (Cambridge, MA, USA). Antibodies against total or phosphorylated AMPK, total or phosphorylated acetyl-CoA carboxylase (ACC) were obtained from Cell Signaling Technology (Beverly, MA, USA). Antibodies against toll-like receptor 4 (TLR4), peroxisome proliferator-activated receptor $\gamma$ (PPAR $\gamma$ ) and HRP-labeled goat anti-rabbit secondary antibody was purchased from Wuhan Sanying Biotechnology Co. Ltd. (Chinese branch). The specific primers, siRNA sequences targeted TLR4 and negative siRNA sequences were synthesized by SangonBiotech Co.,Ltd. (Shanghai, China).The concentration of inhibitors or agonist used in the present study was determined according to previous studies and our preliminary studies.

\section{KARGER}




\section{Cellular Physiology Cell Physiol Biochem 2017;42:1227-1239 \begin{tabular}{ll|l} 
and Biochemistry & $\begin{array}{l}\text { DOI: 10.1159/000478920 } \\
\text { Published onlıne: July 03, } 2017\end{array}$ & $\begin{array}{l}\text { () } 2017 \text { The Author(s). Published by S. Karger AG, Basel } \\
\text { www.karger.com/cpb }\end{array}$ \\
\hline
\end{tabular} \\ Sun et al.: Hypaphorine in Endothelial Inflammation}

\section{Cell culture}

Human EA.hy926 endothelial cells were cultured in DMEM medium supplemented with $10 \%$ bovine serum and incubated at $37{ }^{\circ} \mathrm{C}$ in a humidified air containing $5 \% \mathrm{CO}_{2}$. The growth medium was replaced every 1-2 day and the cells were seeded onto petridishes or multiwell plates at a ratio of 1 to 3 upon $80 \%$ confluency.

\section{Real-time quantitative PCR analysis}

Total RNA was collected using Trizol reagent. Equal RNA levels $(0.5 \mu \mathrm{g})$ from each sample were reversed transcribed into cDNA using HiScriptQ RT SuperMix for qPCR (Vazyme, Nanjing, China). The real-time quantitative PCR was conducted using ChamQTM SYBR ${ }^{\circledR}$ qPCR Master Mix (Vazyme, Nanjing, China).The mRNA levels of tumor necrosis factor- $\alpha$ (TNF- $\alpha$ ), interleukin-1 $\beta$ (IL-1 $\beta$ ), vascular cellular adhesion molecule-1 (VCAM-1) and monocyte chemoattractant protein 1 (MCP-1) were detected by a fluorescence quantitative LightCycler 480 Real Time PCR system (Roche, Basel, Sweden). The relative quantification of gene expression was calculated by using the $2^{-\Delta \Delta C t}$ method. The sequences of primers were listed in the table Table 1.

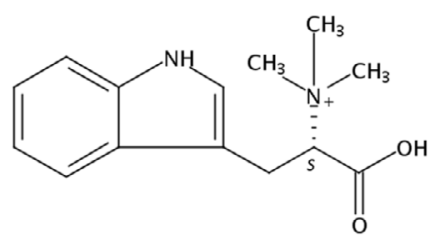

Fig. 1. Chemical structures of investigated vaccaria hypaphorine (VH).

Table 1. Primer for RT-PCR analysis. Note: GAPDH, glyceraldehyde phosphate dehydrogenase; TNF- $\alpha$, tumor necrosis factor- $\alpha$; IL-1 $\beta$, interleukin- $1 \beta$; MCP1 , monocyte chemoattractant protein 1 ; VCAM-1, vascular cellular adhesion molecule-1

\begin{tabular}{ll}
\hline Primers & Sequences $\left(5^{\prime}-3^{\prime}\right)$ \\
\hline GAPDH (Forward) & CCACATCGCTCAGACACCAT \\
GAPDH (Reverse) & CCAGGCGCCCAATACG \\
TNF- $\alpha$ (Forward) & TGCTGCACTTTGGAGTGATCG \\
TNF- $\alpha$ (Reverse) & TGTCACTCGGGGTTCGAGAAG \\
IL-1 $\beta$ (Forward) & TCCAGGGACAGGATATGGAG \\
IL-1 $\beta$ (Reverse) & TCTTTCAACACGCAGGACAG \\
MCP-1 (Forward) & GATGCAATCAATGCCCCAGTC \\
MCP-1 (Reverse) & TCCTTGGCCACAATGGTCTTG \\
VCAM-1 (Forward) & TTGCTGACAGCTGACCTTTG \\
VCAM-1 (Reverse) & TTTAGGCCACATTGGGAAAG \\
\hline
\end{tabular}

\section{Western blotting analysis}

The stimulated cells were lysed and the protein concentration of the cell lysates was measured using BCA Protein Assay Kit (Beyotime, Nanjing, China). Equal amount of proteins lysates were separated onto sodium dodecyl sulfate (SDS)-polyacrylamide gel electrophoresis and electro-transferred onto nitrocellulose membrane (Millipore, Darmstadt, Germany). The blots were then subsequently incubated with the corresponding secondary antibodies conjugated to horseradish peroxidase. The positive bands were visualized by enhanced chemiluminescence (Millipore Darmstadt, Germany). Data were normalized to GAPDH.

\section{Immunofluorescence staining}

After treatment, the cells were fixed with $4 \%$ formaldehyde for $30 \mathrm{~min}$, and then permeabilized with $0.1 \%$ Triton X-100 in PBS for 15 min. After incubation with 10\% goat serum for $30 \mathrm{~min}$, and incubated with indicated primary antibody rabbit anti-TLR4 or PPAR- $\gamma$ overnight at $4{ }^{\circ} \mathrm{C}$. The cells were then incubated with goat anti-rabbit IgG H\&L Alexa Fluor ${ }^{\circledR} 488$ for 30 minutes. Nuclei were stained with 4',6-diamidino-2phenylindole (DAPI) after immunofluorescence staining. Immunofluorescence signals were visualized on a fluorescence microscope (80i, Nikon, Japan).

\section{SiRNA transfections}

Human endothelial EA.hy926 cells were seeded onto six wells an initial density of $10^{5}$ cells/ ml to form a monolayer on the day before the transfection. Cells at 30-40\% confluent were washed and suspended in fresh medium without antibiotics and transfected separately with siRNA-TLR4 (100 $\mathrm{nM})$, scramble (control) siRNA (100 nM) by using Lipofectamine 2000 (Invitrogen, Carlsbad, CA, USA) following the manufacturer's protocols. After 6 hours of incubation, the medium was changed by fresh medium supplemented with $10 \%$ serum and antibiotics. Cells were incubated with LPS for an additional 48 hours. The siRNA sequences targeted TLR4 were as follows: sense, 5'-GGGCUUAGAACAACUAGAATT-3'; antisense, 5'-UUCUAGUUGUUCUAAGCCCTT-3'. The control siRNA sequences were as follows: sense, 5'-UUCUCCGAACGUGUCACGUTT-3'; antisense, 5'- ACGUGACACGUUCGGAGAATT-3'. The siRNA targeted TLR4 has been demonstrated to exhibit the most efficient silencing of TLR4 as previous report [21]. 
Statistical analysis

All results were defined as mean \pm S.D. Comparisons within two groups were made by Student's t test. Statistical analysis was performed by ANOVA/Dunnet t-test for multiple group comparisons. A difference of $\mathrm{P}<0.05$ was considered statistically significant.

\section{Results}

Effects of VH on the inflammatory response in LPS-treated EA.hy926 cells

Endothelialinflammation isinitiatedand deteriorated by overproduction ofinflammatory mediators [22, 23]. LPS is recognized as a danger signal that induces endothelial dysfunction $[24,25]$. To examine whether VH exerted anti-inflammatory actions in human endothelial cells, the endothelial EA.hy926 cells were incubated with different concentrations of VH. Treatment of endothelial EA.hy926 cells with LPS time-dependently upregulated the mRNA levels of TNF- $\alpha$, IL-1 $\beta$, VCAM- 1 and MCP-1 (Fig. 2A). Different doses of VH had no significant effect on TNF- $\alpha$, IL-1 $\beta$, VCAM-1 and MCP-1 mRNA expressions in endothelial cells (Fig. 2B). However, the increased TNF- $\alpha$, IL-1 $\beta$, VCAM- 1 and MCP-1 levels in endothelial cells response to LPS were obviously prevented by VH in a dose-related manner (Fig. 2C). Interestingly, only middle or high dose of VH was able to inhibit the expressions of TNF- $\alpha$, IL-1 $\beta$, VCAM- 1 and MCP-1 in LPS-challenged endothelial cells, thus the high dose of VH $(200 \mu \mathrm{M})$ was selected for the next research in vitro.

TLR4 inhibition was involved in the anti-inflammatory roles of VH

Toll-like receptors complex (TLRs) signalling pathways, particularly TLR4, are activated by LPS, which induces excessive expressions of inflammatory cytokines [26]. We next determined whether TLR4 was involved in the anti-inflammatory roles of VH on EA.hy926 cells. Incubation of endothelial EA.hy926 cells with LPS obviously triggered the protein

Fig. 2. Effects of $\mathrm{VH}$ on the mRNA expressions of TNF- $\alpha$, IL- $1 \beta$, VCAM1 and MCP-1 response to LPS-treated EA.hy926 cells in vitro. (A) Effects of LPS (500 ng/ml at different time points) on TNF- $\alpha$, IL- $1 \beta$, VCAM- 1 and MCP-1 levels in EA.hy926 cells. (B) Effects of different doses of $\mathrm{VH}(0,50$, 100 and $200 \mu \mathrm{M}$ for $48 \mathrm{~h}$ ) on the mRNA expressions of TNF- $\alpha$, IL-1 $\beta$, VCAM-1 and MCP-1 in EA.hy926 cells. (C) Effects of different doses of $\mathrm{VH}(50,100$ and $200 \mu \mathrm{M}$ ) on TNF- $\alpha$, IL-1 $\beta$, VCAM-1 and MCP1 mRNA expressions in LPS (500 ng/ml)-treated EA.hy926 cells. The EA.hy926 cells were pre-

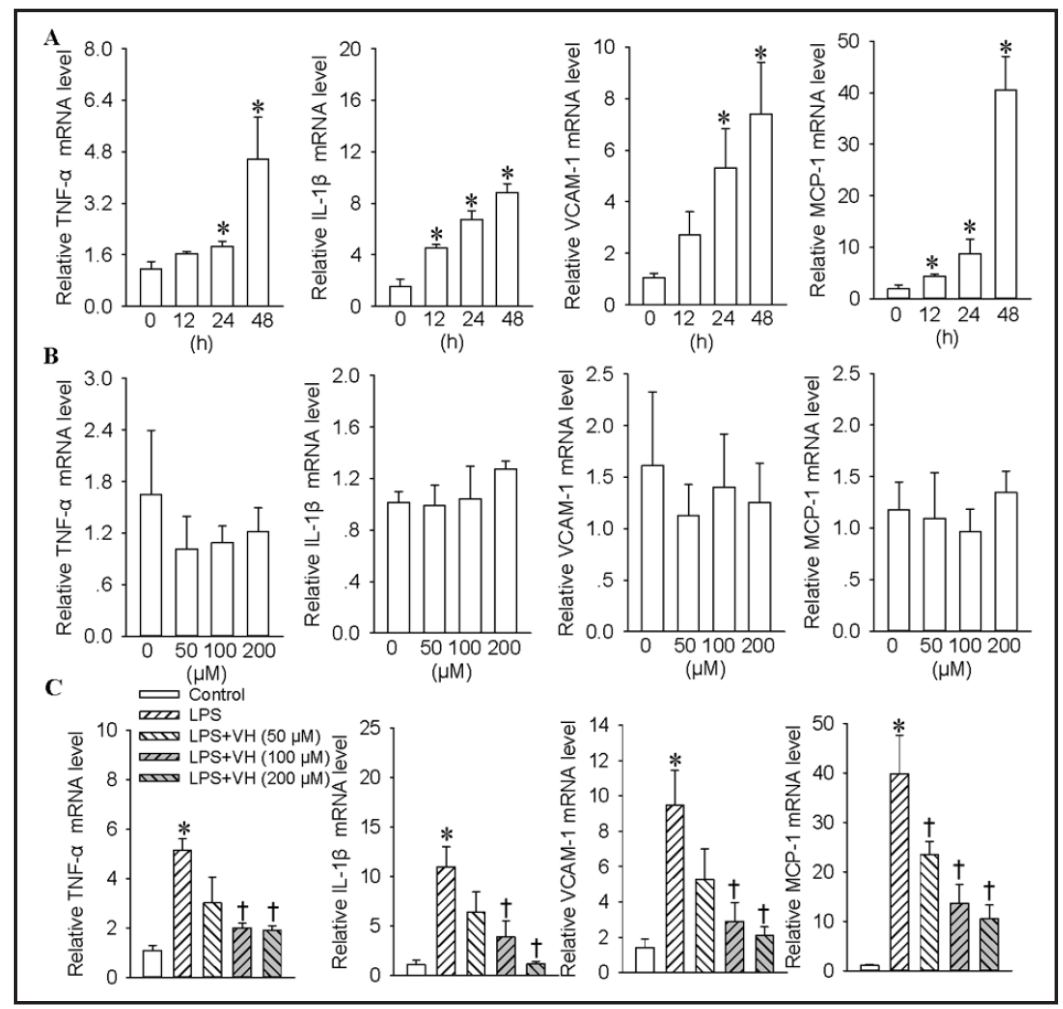
treated with different doses of VH for $6 \mathrm{~h}$ before LPS incubation for another $48 \mathrm{~h}$. Values are mean \pm S.D. ${ }^{*} \mathrm{P}<0.05$ vs. 0 h, $0 \mu \mathrm{M}$ or Control, $+\mathrm{P}<0.05$ vs. LPS. $\mathrm{n}=4$ for each group. 
Fig. 3. Inhibition of TLR4 was involved in the anti-inflammatory roles of VH on EA.hy926 cells response to LPS. (A,D) Effects of LPS (500 $\mathrm{ng} / \mathrm{ml}$ at various time points) on TLR4 protein levels in EA.hy926 cells. (B,E) Effects of different doses of $\mathrm{VH}$ $(0,50,100$ and $200 \mu \mathrm{M}$ for $48 \mathrm{~h}$ ) on TLR4 protein levels in EA.hy926 cells. (C,F) Effects of VH $(200 \mu \mathrm{M})$ on TLR4 protein expressions in LPS $(500 \mathrm{ng} / \mathrm{ml})$-challenged EA.hy926 cells. The EA.hy926 cells were pretreated with $\mathrm{VH}$ for $6 \mathrm{~h}$ before LPS incubation for another $48 \mathrm{~h}$. (G) Immunofluorescence staining showing effects of VH $(200 \mu \mathrm{M})$ on TLR4 protein expressions in EA.hy926 cells response to LPS (500 ng/ $\mathrm{ml}$ ), blue fluorescence (DAPI) shows cell nuclei and green fluorescence

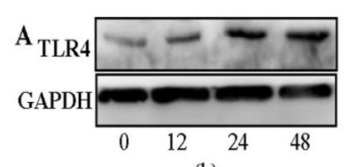

B (h)
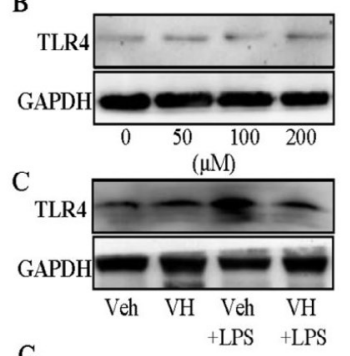

G

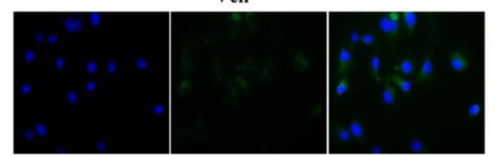

Veh+LPS

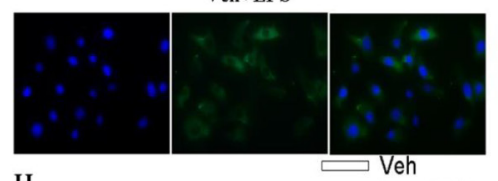

$\mathrm{H}$

एU Con SIRNA $\square$ Con SIRNA+LPS

TLR4 SIRNA TLR4 SIRNA+LPS

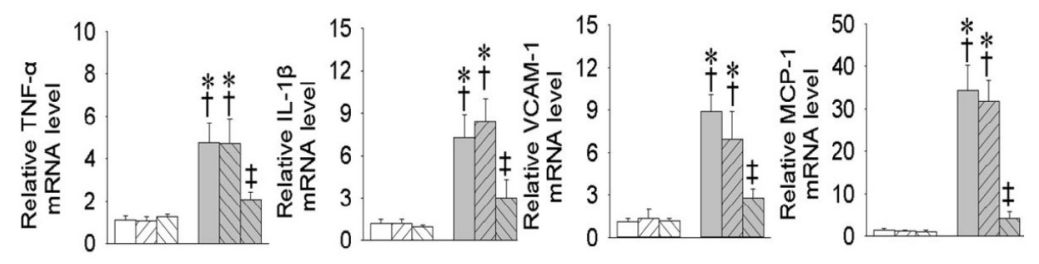

stands for positive cells with TLR4. (H) The EA.hy926 cells were transfected with $100 \mathrm{nM}$ Control (Con) siRNA or TLR 4 siRNA for $24 \mathrm{~h}$, and then were incubated with LPS $(500 \mathrm{ng} / \mathrm{ml})$ for $48 \mathrm{~h}$. The mRNA expressions of TNF- $\alpha$, IL-1 $\beta$, VCAM- 1 and MCP- 1 were detected by real time PCR. Values are mean \pm S.D. ${ }^{*}$ P $<0.05$ vs. $0 \mathrm{ng} /$ $\mathrm{ml}$ or Veh (Vehicle), $\uparrow \mathrm{P}<0.05$ vs. VH or Con siRNA (Control siRNA), $\ddagger \mathrm{P}<0.05$ vs. Veh $+\mathrm{LPS}$ or Con siRNA+LPS. $\mathrm{n}=4$ for each group.

expressions of TLR4 in a time-dependent fashion (Fig. 3A and 3D), VH, by itself, had no direct effect on TLR4 protein expressions (Fig. 3B and 3E). Nevertheless, pretreatment with VH significantly abolished LPS-mediated up-regulation of TLR4 (Fig. 3C and 3F). In addition, immunofluorescence assay further demonstrated that $\mathrm{VH}$ could restrain the immunoreactivity of TLR4 in LPS-stimulated endothelial EA.hy926 cells (Fig. 3G). Importantly, knockdown of TLR4 by siRNA inhibited the expressions of TNF- $\alpha$, IL-1 $\beta$, VCAM-1 and MCP- 1 in EA.hy 926 cells in response to LPS (Fig. 3H).

\section{Activation of PPAR mediated the protective effects of $\mathrm{VH}$}

PPAR $\gamma$ is a nuclear receptor of ligand-activated transcriptional factors, and plays protective roles against endothelial inflammation in atherosclerosis [27, 28]. To further explore the possibility that VH may increase endothelium-derived PPAR $\gamma$ to retard LPSinduced inflammation response, we measured the PPAR $\gamma$ protein expressions in $\mathrm{VH}$ incubated endothelial cells. The protein levels of PPAR $\gamma$ were significantly reduced in the EA.hy926 cells upon exposure to LPS (Fig. 4A and 4D), VH had no effect on protein levels (Fig. 4B and 4E). However, the down-regulation of PPAR $\gamma$ response to LPS was obviously 


\section{Cellular Physiology Cell Physiol Biochem 2017;42:1227-1239 \begin{tabular}{l|l|l} 
DOI: 10.1159/000478920 & O 2017 The Author(s). Published by S. Karger AG, Basel \\
www.karger.com/cpb
\end{tabular}

Fig. 4. Activation of PPAR $\gamma$ mediated the protective effects of VH against LPS-evoked inflammation in EA.hy926 cells. $(A, D)$ Effects of LPS (500 ng/ $\mathrm{ml}$ for various time points) on PPAR $\gamma$ protein levels in EA.hy926 cells. (B,E) Effects of different doses of $\mathrm{VH}(0$, 50, 100 and $200 \mu \mathrm{M}$ for 48 h) on PPAR $\gamma$ protein levels in EA.hy926 cells. (C,F) Effects of $\mathrm{VH}(200 \mu \mathrm{M})$ on PPAR $\gamma$ protein expressions in LPS (500 ng/ ml)-challenged EA.hy926 cells. The EA.hy926 cells were pretreated with VH for $6 \mathrm{~h}$ before LPS incubation for another 48 h. (G) Immunofluorescence staining showing effects of $\mathrm{VH}$ $(200 \mu \mathrm{M})$ on PPAR $\gamma$ expressions in EA.hy926 cells response to LPS (500 ng/ml), blue fluorescence (DAPI) shows cell nuclei and green fluorescence stands for positive cells with PPAR $\gamma$. (H) The EA.hy926 cells were pretreated with pioglitazone $(20 \mu \mathrm{M})$ for $6 \mathrm{~h}$, and then

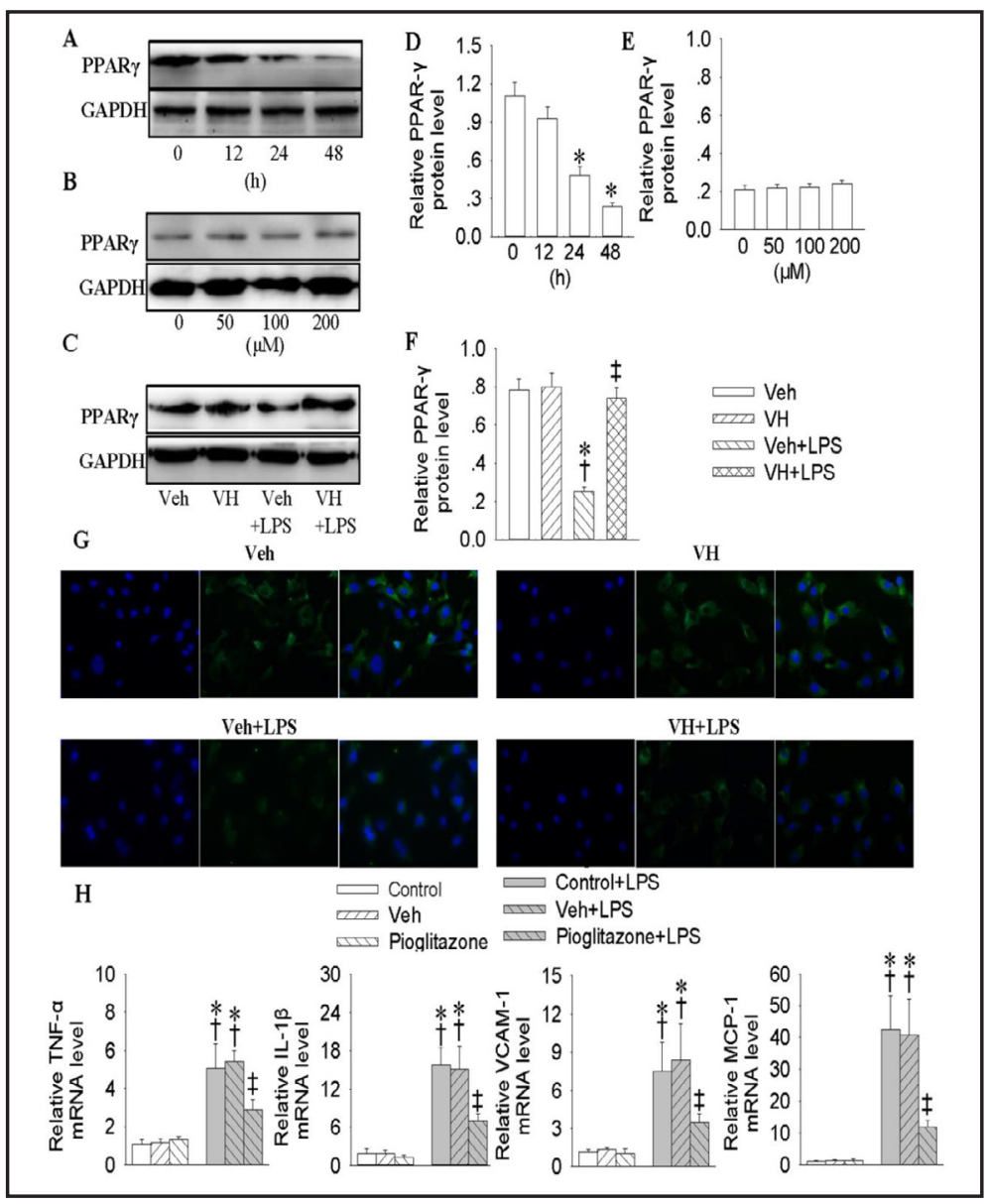
were stimulated with LPS $(500 \mathrm{ng} / \mathrm{ml})$ for another $48 \mathrm{~h}$. The mRNA expressions of TNF- $\alpha$, IL-1 $\beta$, VCAM-1 and MCP- 1 were detected by real time PCR. Values are mean \pm S.D. ${ }^{*} \mathrm{P}<0.05 \mathrm{vs} .0 \mathrm{ng} / \mathrm{ml}$ or Veh (Vehicle), $\dagger \mathrm{P}<0.05$ vs. VH or Control, $\neq \mathrm{P}<0.05$ vs. Veh+LPS or Control+LPS. $\mathrm{n}=4$ for each group.

rescued by $\mathrm{VH}$, as evidenced by Western blotting (Fig. 4C and 4F) or immunofluorescence staining (Fig. 4G). Furthermore, PPAR $\gamma$ agonist pioglitazone suppressed LPS induced upregulations of TNF- $\alpha$, IL-1 $\beta$, VCAM-1 and MCP-1 in EA.hy926 cells (Fig. 4H).

\section{Crosstalk between PPAR $y$ and TLR4 in EA.hy926 cells in response to LPS}

PPAR $\gamma$ activation diminished the proliferation of esophageal cancer cells via TLR4dependent MAPK signalling pathway [29]. Toll-like receptor (TLR) agonists reduce the mRNA, protein levels and activity of PPAR $\gamma$, which is crucial for inflammation response in rat brain astrocytes [30]. These existing researches leaded us to investigate whether reciprocation between PPAR $\gamma$ and TLR4 contributed to inflammation in LPS-stimulated endothelial EA.hy926 cells. As expected, we observed that LPS-induced increased TLR4 protein expressions were inhibited by PPAR $\gamma$ agonist pioglitazone (Fig. 5A), but the downregulated PPAR $\gamma$ expressions in response to LPS were partially restored by pretreatment of TLR4 siRNA (Fig. 5B).

AMPKsignalling pathway is involved in inhibitory effect of VH on LPS-induced inflammation

AMP-activated protein kinase (AMPK) activation counteracts endothelial injury in endothelial cells [31-33]. C1q/TNF-related protein 9 is shown to alleviate TNF $\alpha$-induced expressions of VCAM-1 and MCP-1 via AMPK activation in endothelial cells [34]. Glucagonlike peptide-1 activates AMPK to exert strong anti-inflammatory effects in human aortic endothelial cells [35]. Thus, we examined whether VH could suppress LPS-induced 

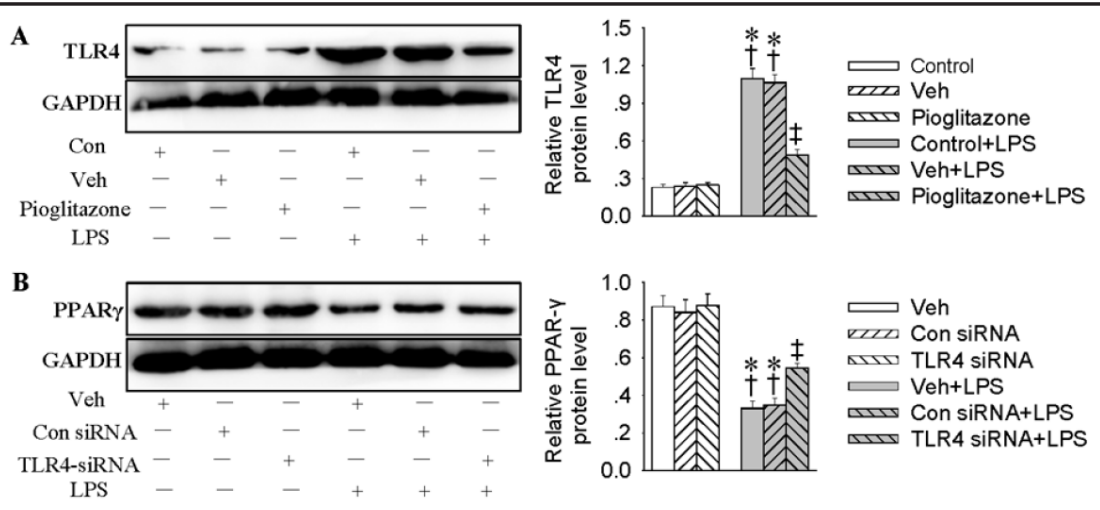

Fig. 5. Crosstalk between PPAR $\gamma$ and TLR4 in EA.hy926 cells in response to LPS. (A) Western blotting of TLR4 in EA.hy926 cells. The EA.hy926 cells were pre-incubated with pioglitazone $(20 \mu \mathrm{M})$ for $6 \mathrm{~h}$ followed by LPS (500 ng/ml) stimulation for $48 \mathrm{~h}$. (B) Western blotting of PPARy in EA.hy926 cells. The EA.hy926 cells were transfected with $100 \mathrm{nM}$ Control siRNA or TLR4 siRNA for $24 \mathrm{~h}$ followed by LPS (500 ng/ml) stimulation for $48 \mathrm{~h}$. Values are mean \pm S.D. ${ }^{*} \mathrm{P}<0.05$ vs. Control or Veh (Vehicle), $\uparrow \mathrm{P}<0.05$ vs. Con siRNA (Control siRNA), $\neq \mathrm{P}<0.05$ vs. Control+LPS or Veh+LPS. $n=4$ for each group.

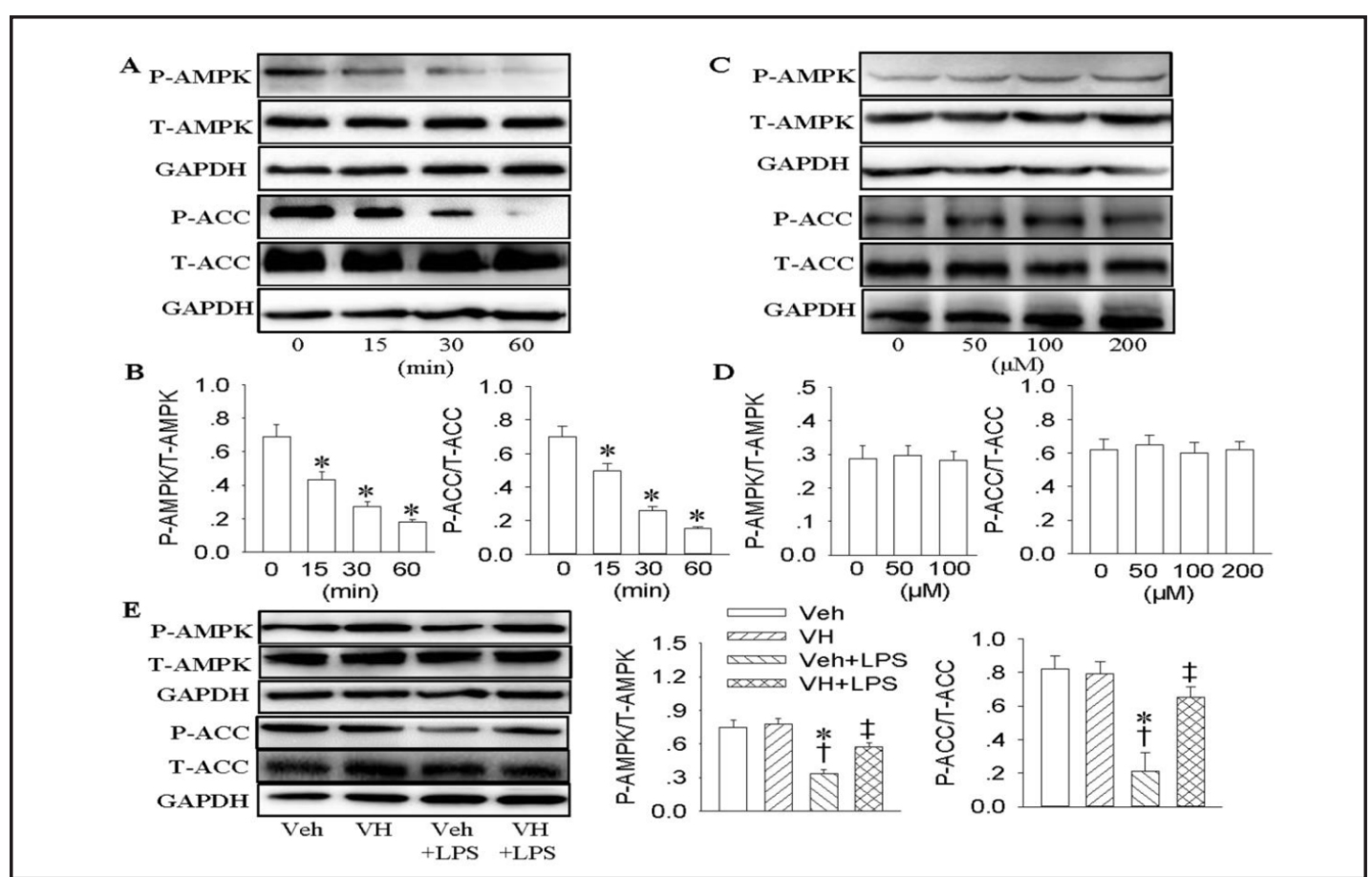

Fig. 6. AMPK signalling pathway is involved in inhibitory effects of VH on LPS-induced inflammation cascade in EA.hy926 cells. (A) Effects of LPS on the protein expressions of AMPK, p-AMPK, ACC and p-ACC at indicated time in EA.hy926 cells. The EA.hy926 cells were stimulated with LPS (500 ng/ml) for 0, 15, 30 or 60 min. (B) Bar graph showing the relative phosphorylated AMPK and ACC levels in response to LPS. (C) Effects of VH on expressions of AMPK, p-AMPK, ACC and p-ACC at indicated doses (0, 50, 100 and $200 \mu \mathrm{M})$ for 60 min in EA.hy926 cells. The EA.hy926 cells were stimulated with different doses $(0,50,100$ and $200 \mu \mathrm{M})$ of $\mathrm{VH}$ for $60 \mathrm{~min}$. (D) Bar graph showing the relative phosphorylated AMPK and ACC levels in response to VH. (E) Effects of VH on the phosphorylated AMPK and ACC in EA.hy926 cells response to LPS. The EA.hy926 cells were pretreated with VH for $6 \mathrm{~h}$ before LPS incubation for $60 \mathrm{~min}$. Values are mean \pm S.D. ${ }^{*} \mathrm{P}<0.05$ vs. 0 min or Veh (Vehicle), $\uparrow \mathrm{P}<0.05$ vs. $V H, \ddagger \mathrm{P}<0.05$ vs Veh+LPS. $\mathrm{n}=4$ for each group.

production of pro-inflammatory factors via AMPK activation in endothelial EA.hy926 cells. Stimulation of endothelial EA.hy 926 cells by LPS reduced the phosphorylation of AMPK and KARGER 
Fig. 7. Effects of AMPK agonist AICAR $(100 \mu \mathrm{M})$ or AMPK activator A769662 (100 $\mu \mathrm{M})$ on mRNA expressions of TNF- $\alpha$, IL-1 $\beta$, VCAM-1 and MCP-1 in LPS-treated EA.hy926 cells. (A) The EA.hy926 cells were pretreated with AICAR $(100 \mu \mathrm{M})$ for $6 \mathrm{~h}$ before LPS incubation for $48 \mathrm{~h}$. The mRNA expressions of TNF- $\alpha$, IL-1 $\beta$, VCAM- 1 and MCP1 were determined by real time PCR. (B) The EA.hy926 cells were pretreated with A769662 $(100 \mu \mathrm{M})$ for $6 \mathrm{~h}$ before LPS incubation for $48 \mathrm{~h}$. The mRNA expressions of TNF- $\alpha$, IL- $1 \beta$, VCAM-1 and MCP-1 were determined by real time PCR. Values are mean \pm S.D. ${ }^{*} \mathrm{P}<0.05$ vs. Con (Control) or Veh (Vehicle), $+\mathrm{P}<0.05$ vs. Con+LPS or Veh+LPS. $n=4$ for each group.

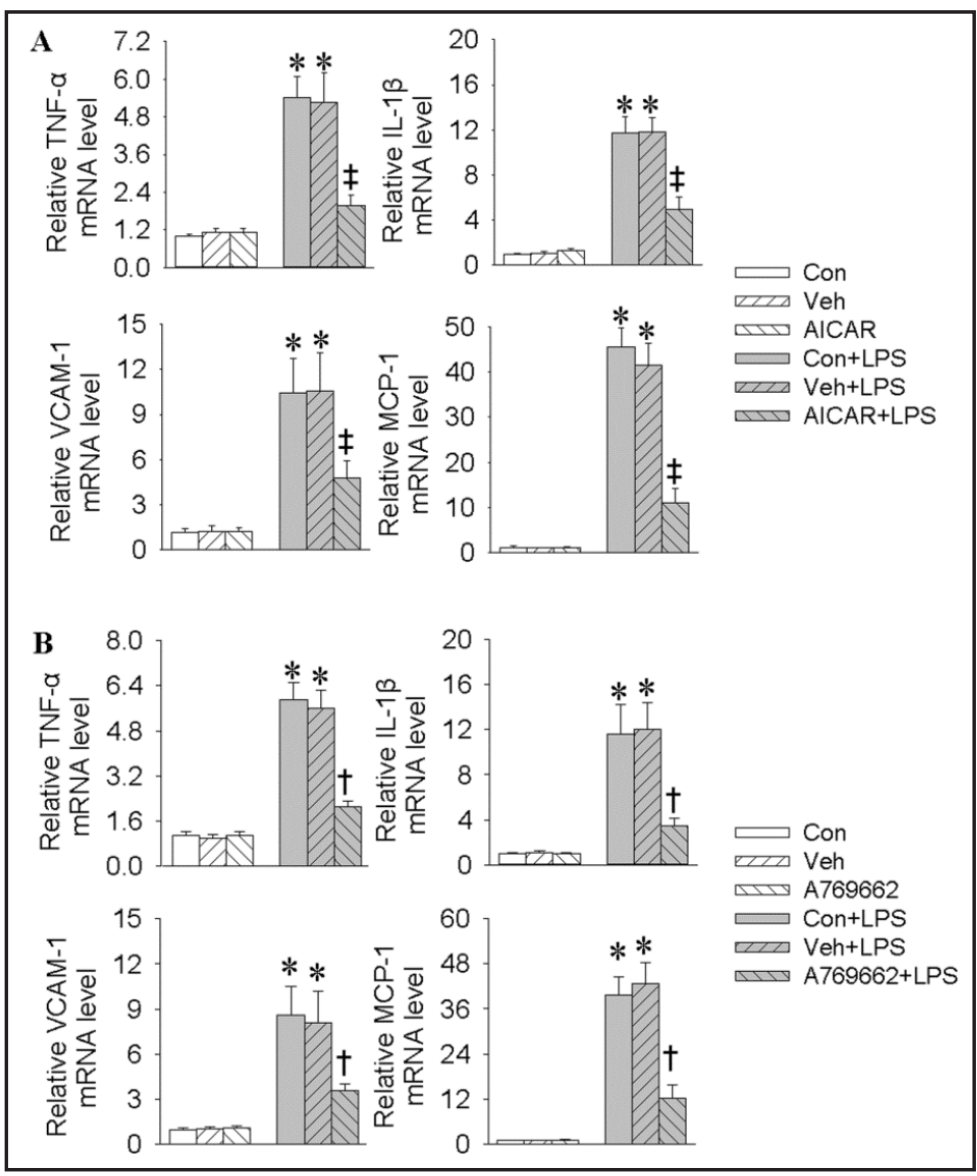

Fig. 8. Effects of AMPK agonist AICAR $(100 \mu \mathrm{M})$ or AMPK activator A769662 (100 $\mu \mathrm{M})$ on protein expressions of TLR4 and PPAR $\gamma$ in LPS-treated EA.hy926 cells. The EA.hy926 cells were pretreated with AICAR (100 $\mu \mathrm{M})$ or A769662 (100 $\mu \mathrm{M})$ for $6 \mathrm{~h}$ before LPS incubation for additional $48 \mathrm{~h}$. (A, B) Effects of AMPK agonist AICAR on TLR4 protein expressions in LPS-incubated endothelial cells. (C, D) Effects of AMPK agonist AICAR on PPAR $\gamma$ protein expressions in LPS-incubated endothelial cells. (E, F) Effects of AMPK activator A769662 on TLR4 protein expressions in LPS-incubated endothelial cells. (G, H) Effects of AMPK activator A769662 on PPAR $\gamma$ protein expressions in
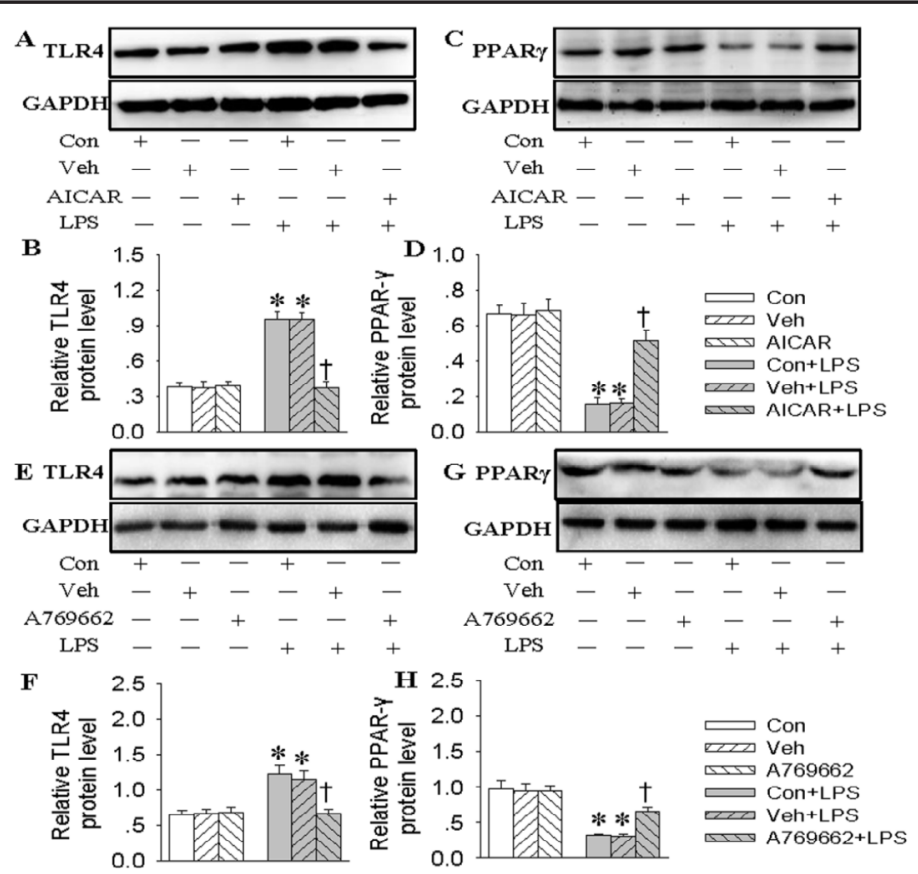

LPS-incubated endothelial cells. Values are mean \pm S.D. $* \mathrm{P}<0.05$ vs. Con (Control) or Veh (Vehicle), $\nmid \mathrm{P}<0.05$ vs. Con+LPS or Veh+LPS. $n=4$ for each group. 
Fig. 9. AMPK signalling was responsible for interactions between PPAR- $\gamma$ and TLR4 in LPS-stimulated EA.hy926 cells. The EA.hy926 cells were pretreated with AMPK inhibitor compound $\mathrm{C}(40 \mu \mathrm{M})$ for 30 min, and then incubated with $\mathrm{VH}$ for $6 \mathrm{~h}$, followed by LPS stimulation for another $48 \mathrm{~h}$. The protein expressions of TLR4 (A, B) and PPAR $\gamma$ (C, D) were detected by western blotting analysis. (E) Inhibition of AMPK with compound $\mathrm{C}$ abolished anti-inflammatory effect of VH on endothelial cells in response to LPS. The mRNA expressions of TNF- $\alpha$, IL- $1 \beta$, VCAM-1 and MCP-1 were detected by real time quantitative PCR. Values are mean \pm S.D. $* \mathrm{P}<0.05$ vs. Control, $\dagger \mathrm{P}<0.05$ vs. Control+LPS, $\neq \mathrm{P}<0.05$ vs $\mathrm{VH}+\mathrm{LPS}$. $\mathrm{n}=4$ for each group.

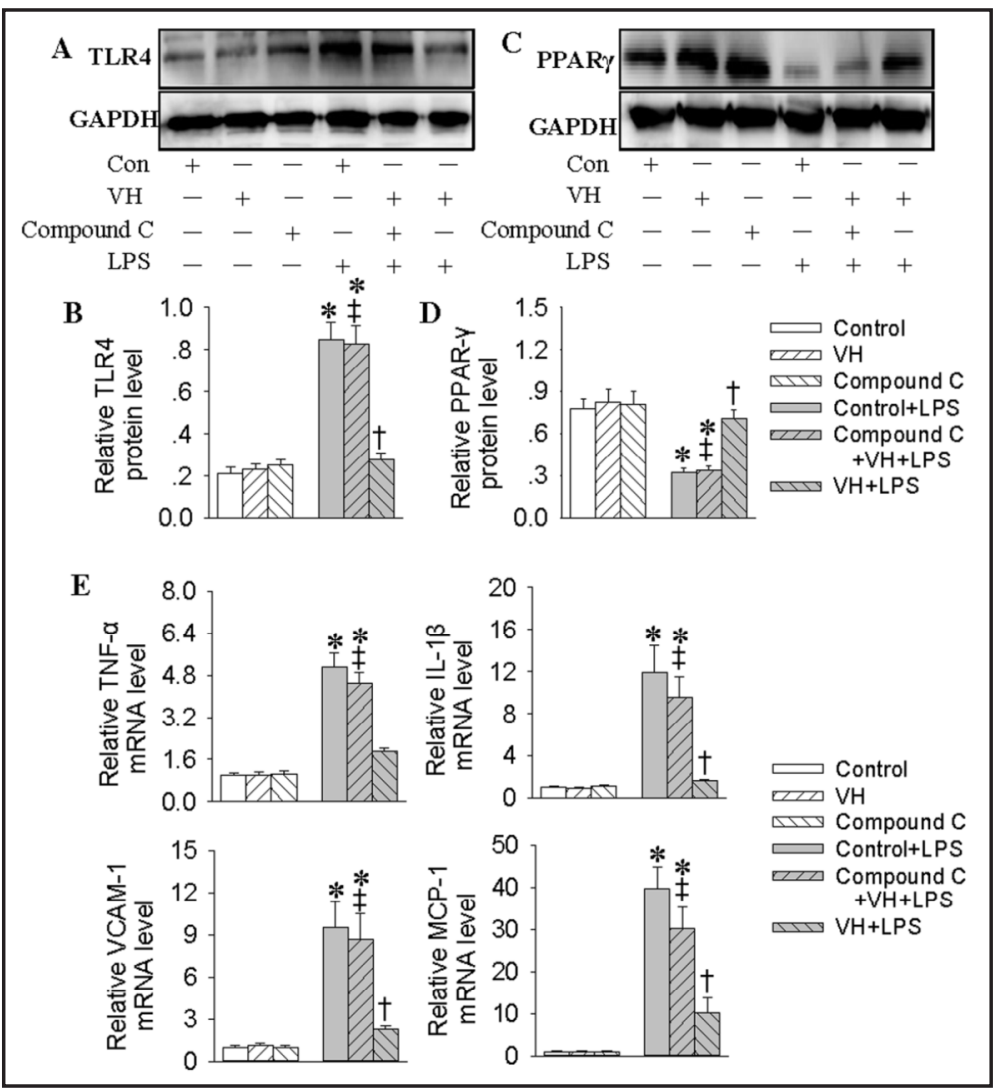

its downstream effector ACC (Fig. 6A and 6B), VH had no effect on the phosphorylation levels of AMPK and ACC (Fig. 6C and 6D). However, VH treatment significantly resisted LPS-induced decreases in phosphorylation of AMPK and ACC (Fig. 6E). Besides, both AMPK agonist AICAR (Fig. 7A) and AMPK activator A769662 (Fig. 7B) significantly impeded the LPS induced overproduction of pro-inflammatory cytokines.

AMPK signalling was responsible for the crosstalk between PPAR $\gamma$ and TLR4

It has been reported that metformin plays a cardioprotective role in LPS-induced sepsis via AMPK-mediated suppression of TLR4 activity [36]. Thymol promotes the expressions of brown fat-specific markers including PPAR $\gamma$ via activation of AMPK signalling [37]. Pretreatment with AMPK agonist AICAR significantly prevented the increased TLR4 protein expressions (Fig. 8A and 8B), but rescued the decreased PPAR $\gamma$ protein levels (Fig. 8C and 8D) in LPS-incubated EA.hy926 cells. Pretreatment with AMPK activator A769662 reversed LPSmediated modulations of TLR4 (Fig. 8E and 8F) and PPAR $\gamma$ (Fig. 8G and 8H). Furthermore, blockade of AMPK with Compound $\mathrm{C}$ abolished the effects of VH on inhibition of TLR4 (Fig. 9A and 9B) or activation of PPAR (Fig. 9C and 9D) in endothelial cells in response to LPS. More important, inhibition of AMPK with Compound C abolished the anti-inflammatory effect of VH on endothelial cells in response to LPS (Fig. 9E).

\section{Discussion}

Endothelial cells are described to maintain homeostasis via modulation of vascular permeability, coagulation, angiogenesis and blood pressure [3]. The endothelium injury leads to recruitment of circulating inflammatory cells into the vessel wall to perpetuate vascular diseases such as atherosclerosis [38]. A better understanding of inflammationinduced endothelial dysfunction may be helpful for developing new therapeutic strategies for 
cardiovascular disorders. In the present study, our primary results showed that VH exerted a protective role against LPS-induced inflammation response in endothelial EA.hy926 cells through regulations of TLR4 and PPAR $\gamma$, dependent AMPK signalling pathways.

Endothelial dysfunction is a prominent feature of cardiovascular diseases and a harbinger of various cardiovascular events [39]. The proinflammatory cytokines are capable of driving endothelial dysfunction, contributing to the progression of cardiovascular events [40]. In this study, our results showed that the increased inflammation cytokines including TNF- $\alpha$, IL-1 $\beta$, VCAM- 1 and MCP- 1 response to LPS were abolished by pretreatment with VH. These results hinted that $\mathrm{VH}$ played a protective role against LPS-inflammation in endothelial EA.hy926 cells.

TLRs belong to a family of highly conserved pathogen recognition receptors, and are key regulators of innate immunity [41]. Endothelial cells have been indicated to express pattern-recognition receptors such as TLR4 with respect to pathogens, damage signals and inflammatory stimulant [3]. It has been established that endothelial cell-derived TLR4, rather than TLR4 from platelets and leukocytes, exerts a pivotal role in the formation of thrombus [42]. In the present study, our data exhibited that the protein levels of TLR4 were increased in endothelial cells exposed to LPS, but VH inhibited the upregulated TLR4 expressions response to LPS. In addition, knockdown of TLR4 by siRNA inhibited the expressions of TNF- $\alpha$, IL-1 $\beta$, VCAM-1 and MCP-1 in LPS-incubated EA.hy926 cells. These results indicated that VH may attenuate LPS-stimulated endothelial inflammation through inhibition of TLR4.

PPAR $\gamma$ is one of the nuclear receptors of ligand-activated transcriptional factors, and PPAR $\gamma$ activation impedes inflammation response in endothelial cells [28]. It is reported that cimiside E, 23-0-actylshengmanol-3-xyloside, isoimperatorin isolated from Cimicifugae Rhizome exhibits anti-inflammatory actions at least by upregulation of PPAR $\gamma$ [43]. In this study, we showed that LPS inhibited the protein levels of PPAR $\gamma$, and VH eliminated LPSinduced suppression of PPAR $\gamma$ expression. Moreover, PPAR $\gamma$ agonist pioglitazone prevented LPS-induced up-regulations of inflammatory cytokines in EA.hy926 cells. These results indicated that VH could block LPS-induced inflammatory cytokines via activating PPAR $\gamma$ in endothelial cells. It is noted that gene silencing of TLR4 reversed the downregulated PPAR $\gamma$ levels in EA.hy926 cells response to LPS, and PPAR $\gamma$ agonist pioglitazone treatment abolished LPS-mediated upregulated TLR4 expressions. These results unveiled that both PPAR $\gamma$ activation and TLR4 suppression may coordinately participate in the protective effects of VH on inflammation cascade in endothelial cells induced by LPS.

AMPK, as an energy sensor, is ubiquitously expressed in vascular cells, and exerts antiatherosclerotic effects associated to suppression of inflammatory responses [44-46]. The beneficial effects of adiponectin on cardiovascular diseases are expected to be partially mediated by activation of AMPK signalling pathway [47]. The DPP-4 inhibitor sitagliptin significantly decreases the expressions of MCP-1 and IL-6 in the aorta of apolipoproteinE-knockout mice via induction of AMPK phosphorylation [48]. C1q/TNF-related protein 9 stimulates the phosphorylation of AMPK and its downstream effector ACC, thus contributing to block cytokine-induced vascular inflammation and leukocyte adhesiveness in human aortic endothelial cells [34]. Our results showed that LPS-stimulated EA.hy926 cells had a lower phosphorylated AMPK and ACC, which was abolished by VH. Activation of AMPK by AICAR or A769662 diminished the excessive expressions of inflammatory cytokines and adhesion molecules in EA.hy926 cells induced by LPS. Moreover, the negative interactions between TLR4 and PPAR $\gamma$ triggered by LPS were modulated by AMPK signalling pathway. These results demonstrated that AMPK-dependent negative feedback loop of TLR4 and PPAR $\gamma$ was critically involved in protective roles of VH in LPS-stimulated endothelial inflammation. It is particularly worth noting that VH itself had no direct effect on TLR4, PPAR $\gamma$ or especially on AMPK activation, but it inhibited LPS-induced changes in these. We speculated that VH exerted functional modulations of TLR4, PPAR $\gamma$ or AMPK activation in LPS-incubated EA.hy926 cells, but not involved in regulating basal TLR4, PPAR $\gamma$ or AMPK under normal physiological condition.

\section{KARGER}




\section{Cellular Physiology Cell Physiol Biochem 2017;42:1227-1239 \begin{tabular}{l|l} 
DOI: 10.1159/000478920 & $\begin{array}{l}\text { O 2017 The Author(s). Published by S. Karger AG, Basel } \\
\text { www.karger.com/cpb }\end{array}$ \\
\cline { 1 - 3 }
\end{tabular} \\ Sun et al.: Hypaphorine in Endothelial Inflammation}

Taken together, our results demonstrated that VH protected EA.hy926 cells against LPS-induced inflammation by activating AMPK signalling pathways, followed by interactive modulations of TLR4 and PPAR $\gamma$. VH may be a candidate therapeutic agent for treatment of inflammation in the vascular endothelium.

\section{Acknowledgments}

We thank the general support of experimental public platform, Wuxi School of Medicine, Jiangnan University. This work was supported in part by grants from Fundamental Research Funds for the Central Universities (grant no. JUSRP51412B; JUSRP11745), Project funded by China Postdoctoral Science Foundation (2017M611688) and Public Health Research Center at Jiangnan University (JUPH201504).

\section{Disclosure Statement}

The authors declare that they have no conflicts of interest.

\section{References}

1 Sun HJ, Hou B, Wang X, Zhu XX, Li KX, Qiu LY: Endothelial dysfunction and cardiometabolic diseases: Role of long non-coding rnas. Life Sci 2016;167:6-11.

2 Gao Q Yao X, Zheng J: Mir-323 inhibits prostate cancer vascularization through adiponectin receptor. Cell Physiol Biochem 2015;36:1491-1498.

-3 Salvador B, Arranz A, Francisco S, Cordoba L, Punzon C, Llamas MA, Fresno M: Modulation of endothelial function by toll like receptors. Pharmacol Res 2016;108:46-56.

-4 Illan Gomez F, Gonzalvez Ortega M, Aragon Alonso A, Orea Soler S, Alcaraz Tafalla Mf, Perez Paredes M, Lozano Almela Mf: Obesity, endothelial function and inflammation: The effects of weight loss after bariatric surgery. Nutr Hosp 2016;33:1340-1346.

-5 Bharadwaj AS, Appukuttan B, Wilmarth PA, Pan Y, Stempel AJ, Chipps TJ, Benedetti EE, Zamora DO, Choi D, David LL, Smith JR: Role of the retinal vascular endothelial cell in ocular disease. Prog Retin Eye Res 2013;32:102-180.

6 Wang L, Wang J, Fang J, Zhou H, Liu X, Su SB: High glucose induces and activates toll-like receptor 4 in endothelial cells of diabetic retinopathy. Diabetol Metab Syndr 2015;7:89.

7 Fang F, Yang Y, Yuan Z, Gao Y, Zhou J, Chen Q Xu Y: Myocardin-related transcription factor a mediates oxldlinduced endothelial injury. Circ Res 2011;108:797-807.

8 Galle J, Hansen-Hagge T, Wanner C, Seibold S: Impact of oxidized low density lipoprotein on vascular cells. Atherosclerosis 2006;185:219-226.

-9 Njock MS, Fish JE: Endothelial mirnas as cellular messengers in cardiometabolic diseases. Trends Endocrinol Metab 2017;28:237-246.

10 Han F, Hui Z, Zhang S, Hou N, Wang Y, Sun X: Induction of haemeoxygenase-1 improves ffa-induced endothelial dysfunction in rat aorta. Cell Physiol Biochem 2015;35:1230-1240.

$\checkmark 11$ Araldi E, Suarez Y: Micrornas as regulators of endothelial cell functions in cardiometabolic diseases. Biochim Biophys Acta 2016;1861:2094-2103.

12 Mauricio MD, Aldasoro M, Ortega J, Vila JM: Endothelial dysfunction in morbid obesity. Curr Pharm Des 2013;19:5718-5729.

13 Kaplan M, Mutlu EA, Benson M, Fields JZ, Banan A, Keshavarzian A: Use of herbal preparations in the treatment of oxidant-mediated inflammatory disorders. Complement Ther Med 2007;15:207-216.

14 Song L, Kang C, Sun Y, Huang W, Liu W, Qian Z: Crocetin inhibits lipopolysaccharide-induced inflammatory response in human umbilical vein endothelial cells. Cell Physiol Biochem 2016;40:443-452. 


\section{Cellular Physiology Cell Physiol Biochem 2017;42:1227-1239 \begin{tabular}{l|l} 
DOI: 10.1159/000478920 & $\begin{array}{l}\text { O 2017 The Author(s). Published by S. Karger AG, Basel } \\
\text { www.karger.com/cpb }\end{array}$ \\
\hline
\end{tabular}}

Sun et al.: Hypaphorine in Endothelial Inflammation

15 Ferrer E: Emerging therapeutic strategies for chronic inflammatory diseases. Drug News Perspect 2006;19:353-358.

- 16 Cittadini A, Monti MG, Petrillo V, Esposito G, Imparato G, Luciani A, Urciuolo F, Bobbio E, Natale CF, Sacca L, Netti PA: Complementary therapeutic effects of dual delivery of insulin-like growth factor-1 and vascular endothelial growth factor by gelatin microspheres in experimental heart failure. Eur J Heart Fail 2011;13:1264-1274.

17 Xie F, Cai W, Liu Y, Li Y, Du B, Feng L, Qiu L: Vaccarin attenuates the human ea.Hy926 endothelial cell oxidative stress injury through inhibition of notch signaling. Int J Mol Med 2015;35:135-142.

18 Qiu Y, Du B, Xie F, Cai W, Liu Y, Li Y, Feng L, Qiu L: Vaccarin attenuates high glucose-induced human ea*hy926 endothelial cell injury through inhibition of notch signaling. Mol Med Rep 2016;13:2143-2150.

19 Qiu Y, Qiu L, Cui J, Wei Q: Bacterial cellulose and bacterial cellulose-vaccarin membranes for wound healing. Mater Sci Eng C Mater Biol Appl 2016;59:303-309.

20 Mollica A, Locatelli M, Stefanucci A, Pinnen F: Synthesis and bioactivity of secondary metabolites from marine sponges containing dibrominated indolic systems. Molecules 2012;17:6083-6099.

-21 Yang H, Yang R, Liu H, Ren Z, Wang C, Li D, Ma X: Knockdown of peroxisome proliferator-activated receptor gamma coactivator-1 alpha increased apoptosis of human endometrial cancer hec-1a cells. Onco Targets Ther 2016;9:5329-5338.

22 Tucker JJ, Wilson MA, Wead WB, Garrison RN: Microvascular endothelial cell control of peripheral vascular resistance during sepsis. Arch Surg 1998;133:1335-1342.

23 Messner B, Bernhard D: Smoking and cardiovascular disease: Mechanisms of endothelial dysfunction and early atherogenesis. Arterioscler Thromb Vasc Biol 2014;34:509-515.

24 Zhou Z, You Z: Mesenchymal stem cells alleviate lps-induced acute lung injury in mice by mir-142a-5pcontrolled pulmonary endothelial cell autophagy. Cell Physiol Biochem 2016;38:258-266.

-25 Yin X, Liang Z, Yun Y, Pei L: Intravenous transplantation of bmp2-transduced endothelial progenitor cells attenuates lipopolysaccharide-induced acute lung injury in rats. Cell Physiol Biochem 2015;35:2149-2158.

-26 Stark RJ, Choi H, Koch SR, Fensterheim BA, Lamb FS, Sherwood ER: Endothelial cell tolerance to lipopolysaccharide challenge is induced by monophosphoryl lipid a. Clin Sci (Lond) 2016;130:451-461.

-27 Su P, Du S, Li H, Li Z, Xin W, Zhang W: Notoginsenoside r1 inhibits oxidized low-density lipoprotein induced inflammatory cytokines production in human endothelial ea.Hy926 cells. Eur J Pharmacol 2016;770:9-15.

28 Balakumar P, Kathuria S: Submaximal ppargamma activation and endothelial dysfunction: New perspectives for the management of cardiovascular disorders. Br J Pharmacol 2012;166:1981-1992.

29 Wu K, Yang Y, Liu D, Qi Y, Zhang C, Zhao J, Zhao S: Activation of ppargamma suppresses proliferation and induces apoptosis of esophageal cancer cells by inhibiting tlr4-dependent mapk pathway. Oncotarget 2016;7:44572-44582.

-30 Chistyakov DV, Aleshin SE, Astakhova AA, Sergeeva MG, Reiser G: Regulation of peroxisome proliferatoractivated receptors (ppar) alpha and -gamma of rat brain astrocytes in the course of activation by toll-like receptor agonists. J Neurochem 2015;134:113-124.

-31 Zhang Y, Qiu J, Wang X, Zhang Y, Xia M: Amp-activated protein kinase suppresses endothelial cell inflammation through phosphorylation of transcriptional coactivator p300. Arterioscler Thromb Vasc Biol 2011;31:2897-2908.

-32 Li J, Li J, Wei T, Li J: Down-regulation of microrna-137 improves high glucose-induced oxidative stress injury in human umbilical vein endothelial cells by up-regulation of ampkalpha1. Cell Physiol Biochem 2016;39:847-859.

-33 Han F, Guo Y, Xu L, Hou N, Han F, Sun X: Induction of haemeoxygenase-1 directly improves endothelial function in isolated aortas from obese rats through the ampk-pi3k/akt-enos pathway. Cell Physiol Biochem 2015;36:1480-1490.

- 34 Jung CH, Lee MJ, Kang YM, Lee YL, Seol SM, Yoon HK, Kang SW, Lee WJ, Park JY: C1q/tnf-related protein-9 inhibits cytokine-induced vascular inflammation and leukocyte adhesiveness via amp-activated protein kinase activation in endothelial cells. Mol Cell Endocrinol 2016;419:235-243.

- 35 Krasner NM, Ido Y, Ruderman NB, Cacicedo JM: Glucagon-like peptide-1 (glp-1) analog liraglutide inhibits endothelial cell inflammation through a calcium and ampk dependent mechanism. PloS One 2014;9:e97554. 


\section{Cellular Physiology Cell Physiol Biochem 2017;42:1227-1239 \begin{tabular}{l|l} 
DOI: 10.1159/000478920 & $\begin{array}{l}\text { O 2017 The Author(s). Published by S. Karger AG, Basel } \\
\text { www.karger.com/cpb }\end{array}$ \\
\hline
\end{tabular} \\ Sun et al.: Hypaphorine in Endothelial Inflammation}

36 Vaez H, Rameshrad M, Najafi M, Barar J, Barzegari A, Garjani A: Cardioprotective effect of metformin in lipopolysaccharide-induced sepsis via suppression of toll-like receptor 4 (tlr4) in heart. Eur J Pharmacol 2016;772:115-123.

37 Choi JH, Kim SW, Yu R, Yun JW: Monoterpene phenolic compound thymol promotes browning of 3t3-l1 adipocytes. Eur J Nutr DOI: 10.1007/s00394-016-1273-2.

- 38 Cahill PA, Redmond EM: Vascular endothelium - gatekeeper of vessel health. Atherosclerosis 2016;248:97109.

-39 Martin BJ, Anderson TJ: Risk prediction in cardiovascular disease: The prognostic significance of endothelial dysfunction. Can J Cardiol 2009;25:S15a-20a.

40 Tziomalos K, Athyros VG, Karagiannis A, Mikhailidis DP: Endothelial dysfunction in metabolic syndrome: Prevalence, pathogenesis and management. Nutr Metab Cardiovasc Dis 2010;20:140-146.

41 Akira S, Uematsu S, Takeuchi O: Pathogen recognition and innate immunity. Cell 2006;124:783-801.

42 Ren M, Li R, Luo M, Chen N, Deng X, Yan K, Zeng M, Wu J: Endothelial cells but not platelets are the major source of toll-like receptor 4 in the arterial thrombosis and tissue factor expression in mice. Am J Physiol Regul Integr Comp Physiol 2014;307:R901-907.

43 Moon L, Ha YM, Jang HJ, Kim HS, Jun MS, Kim YM, Lee YS, Lee DH, Son KH, Kim HJ, Seo HG, Lee JH, Kim YS, Chang KC: Isoimperatorin, cimiside e and 23-o-acetylshengmanol-3-xyloside from cimicifugae rhizome inhibit tnf-alpha-induced vcam-1 expression in human endothelial cells: Involvement of ppar-gamma upregulation and pi3k, erk1/2, and pkc signal pathways. J Ethnopharmacol 2011;133:336-344.

-44 Sung JY, Choi HC: Nifedipine inhibits vascular smooth muscle cell proliferation and reactive oxygen species production through amp-activated protein kinase signaling pathway. Vascul Pharmacol 2012;56:1-8.

45 Xu Q, Si LY: Protective effects of amp-activated protein kinase in the cardiovascular system. J Cell Mol Med 2010;14:2604-2613.

-46 Ou HC, Hsieh YL, Yang NC, Tsai KL, Chen KL, Tsai CS, Chen IJ, Wu BT, Lee SD: Ginkgo biloba extract attenuates oxldl-induced endothelial dysfunction via an ampk-dependent mechanism. J Appl Physiol (1985) 2013;114:274-285.

47 Rojas E, Rodriguez-Molina D, Bolli P, Israili ZH, Faria J, Fidilio E, Bermudez V, Velasco M: The role of adiponectin in endothelial dysfunction and hypertension. Curr Hypertens Rep 2014;16:463.

48 Zeng Y, Li C, Guan M, Zheng Z, Li J, Xu W, Wang L, He F, Xue Y: The dpp-4 inhibitor sitagliptin attenuates the progress of atherosclerosis in apolipoprotein-e-knockout mice via ampk- and mapk-dependent mechanisms. Cardiovasc Diabetol 2014;13:32. 